\title{
Health-related quality of life outcomes and level of evidence in pediatric neurosurgery
}

\author{
Daniel Hansen, MD, Aditya Vedantam, MD, Valentina Briceño, RN, Sandi K. Lam, MD, MBA, \\ Thomas G. Luerssen, MD, and Andrew Jea, MD

\begin{abstract}
Division of Pediatric Neurosurgery, Texas Children's Hospital, Department of Neurosurgery, Baylor College of Medicine,
\end{abstract} \\ Houston, Texas
}

\begin{abstract}
OBJECTIVE The emphasis on health-related quality of life (HRQOL) outcomes is increasing, along with an emphasis on evidence-based medicine. However, there is a notable paucity of validated HRQOL instruments for the pediatric population. Furthermore, no standardization or consensus currently exists concerning which HRQOL outcome measures ought to be used in pediatric neurosurgery. The authors wished to identify HRQOL outcomes used in pediatric neurosurgery research over the past 10 years, their frequency, and usage trends.
\end{abstract}

METHODS Three top pediatric neurosurgical journals were reviewed for the decade from 2005 to 2014 for clinical studies of pediatric neurosurgical procedures that report HRQOL outcomes. Similar studies in the peer-reviewed journal Pediatrics were also used as a benchmark. Publication year, level of evidence, and HRQOL outcomes were collected for each article.

RESULTS A total of $31 \mathrm{HRQOL}$ studies were published in the pediatric neurosurgical literature over the study period. By comparison, there were 55 such articles in Pediatrics. The number of publications using HRQOL instruments showed a significant positive trend over time for Pediatrics $(B=0.62, p=0.02)$ but did not increase significantly over time for the 3 neurosurgical journals $(B=0.12, p=0.5)$. The authors identified a total of 46 different HRQOL instruments used across all journals. Within the neurosurgical journals, the Hydrocephalus Outcome Questionnaire (HOQ) (24\%) was the most frequently used, followed by the Health Utilities Index (HUI) (16\%), the Pediatric Quality of Life Inventory (PedsQL) (12\%), and the 36-Item Short Form Health Survey (SF-36) (12\%). Of the 55 articles identified in Pediatrics, 22 (40\%) used a version of the PedsQL. No neurosurgical study reached above Level 4 on the Oxford Centre for Evidence-Based Medicine (OCEBM) system. However, multiple studies from Pediatrics achieved OCEBM Level 3, several were categorized as Level 2, and one reached Level 1.

CONCLUSIONS The frequency of studies using HRQOL outcomes in pediatric neurosurgical research has not increased over the past 10 years. Within pediatric neurosurgery, high-quality studies and standardization are lacking, as compared with contemporary studies in Pediatrics. In general, although the HOQ, HUI, PedsQL, and SF-36 instruments are emerging as standards in pediatric neurosurgery, even greater standardization across the specialty is needed, along with the design and implementation of more rigorous studies.

http://thejns.org/doi/abs/10.3171/2016.3.PEDS15641

KEY WORDS surgical outcomes; patient-reported outcomes; health-related quality of life; level of evidence; pediatric neurosurgery

$\mathrm{S}$ TUDIES of outcomes in pediatric neurosurgery can demonstrate treatment effectiveness. They have the potential to enable pediatric health care providers, patients, and patients' families to make informed decisions. Since the Patient Protection and Affordable Care Act (PPACA) was signed into law in 2010, there has been a renewed focus on physician reimbursement and, in particular, a shift toward pay-for-performance reimbursement. This overhaul to the health care system has prompted all participants, insurance companies, hospitals, and regulatory bodies to push for cost-effective and evidence-based treatments. Outcome studies will provide the data necessary to assess patient-reported and familyreported outcomes. This information may drive utiliza-

ABBREVIATIONS HOQ = Hydrocephalus Outcome Questionnaire; HRQOL = health-related quality of life; HUI = Health Utilities Index; LOE = level of evidence; OCEBM = Oxford Centre for Evidence-Based Medicine; PedsQL = Pediatric Quality of Life; PPACA = Patient Protection and Affordable Care Act; SF-36 = 36-Item Short Form Health Survey.

SUBMITTED March 8, 2016. ACCEPTED March 30, 2016.

INCLUDE WHEN CITING Published online June 24, 2016; DOI: 10.3171/2016.3.PEDS15641. 
tion of the most effective patient-centered neurosurgical treatments in children and ensure that treatment quality is maintained and not sacrificed in the face of rising economic pressures. ${ }^{9}$

Current outcome studies in pediatric neurosurgery frequently report patient demographic data, clinical and operative data, and complication rates, but few report healthrelated quality of life (HRQOL) outcomes using validated tools. Robust HRQOL outcomes data are important for clinical outcome and cost-effectiveness studies, because they most closely reflect the basis of treatment-to improve quality of life for the patient. The purpose of our study was to perform a thorough review of HRQOL outcomes instrument use in the pediatric neurosurgical literature, in an effort to highlight trends and pattern usage. Our aim was for the results to aid authors deciding among HRQOL measures for clinical studies, or professional societies and governing bodies drafting guidelines to standardize the use of HRQOL outcomes measures in pediatric neurosurgical research. We used HRQOL articles in Pediatrics as a benchmark for citation and content analysis. To the best of our knowledge, no bibliometric analysis of the pediatric neurosurgical literature with a concentration on HRQOL outcome use has previously been published.

\section{Methods}

Three top pediatric neurosurgical journals (Journal of Neurosurgery: Pediatrics, Child's Nervous System, and Pediatric Neurosurgery) were identified by readership and impact factor. The titles of all clinical studies published in these journals between 2005 and 2014 were reviewed on PubMed. Likewise, the journal Pediatrics was chosen as a control; published clinical articles during the same period were reviewed using the online Pediatrics archive. This nonsurgical journal was chosen as a benchmark comparison due to breadth of readership and on the assumption that it provides a good representation of publishing trends within the pediatric field in general. Neurosurgical articles were included if the title referred to a surgical procedure in a clinical study with outcomes measured by any HRQOL outcomes tool. The total pool of articles for the Journal of Neurosurgery: Pediatrics, Child's Nervous System, and Pediatric Neurosurgery was 2106, 2753, and 789, respectively. Over the same time period, there were 8420 articles published in Pediatrics. Articles in Pediatrics were included if they referenced any HRQOL outcomes tool or measurement of QOL. If these criteria could not be clearly assessed from the title alone, the abstract was reviewed for references to HRQOL measures. Using the title as the primary screening method ensured that identified articles emphasized the reporting and analysis of HRQOL measures. Articles meeting these criteria were reviewed in full. The title, author, year of publication, sample size, general diagnosis, and HRQOL outcomes instruments used were recorded for all reviewed articles.

After a careful review of the abstracts, we assigned a level of evidence (LOE) according to the definitions provided by the Oxford Centre for Evidence-Based Medicine (OCEBM) (http://www.cebm.net/ocebm-levels-ofevidence/). In brief, articles were assessed to determine what row of the OCEBM table they aimed to address, and then they were matched to an LOE column based on study design. This resulted in an assigned LOE. If we were unable to assign a value from the abstract, the entire article was reviewed. Articles of all LOEs (1-5) were included in our study. To further guide our assignment of LOE values, both the background and introductory documents provided by the OCEBM were used. In the event that there was a rating discrepancy between the authors of the current paper, the article was jointly reviewed, and an agreed-upon rating was assigned.

This study included articles in which the diagnosis of any pediatric neurosurgical disorder such as hydrocephalus, brain tumor, and spina bifida was discussed. Articles in Pediatrics included the full gamut of diagnoses, such as psychological trauma due to bullying, congenital heart disease, and depression, which are incorporated in the practice of any pediatric subspecialist. Trends in HRQOL outcomes usage over time were reported. The number of HRQOL outcomes studies in each journal was reported, along with the frequency of each LOE.

\section{Data Analysis}

Descriptive statistics, including mean, standard deviation, standard error, and confidence intervals, were computed as necessary. Differences in the mean number of publications and publication proportions of HRQOL studies between journals were detected using the t-test and $\mathrm{z}$ test, respectively. Linear regression analysis was used to determine trends over time for the number of publications with HRQOL instruments. The $\mathrm{p}$ values were considered significant at $<0.05$. Analysis was done using SPSS Statistics (version 21, IBM Corp.).

\section{Results}

Over the past 10 years (2005-2014), the Journal of Neurosurgery: Pediatrics (11 articles), Child's Nervous System (18 articles), and Pediatric Neurosurgery (2 articles) published a total of 31 articles primarily reporting the use of HRQOL instruments. In the same study period, Pediatrics published 55 articles in which HRQOL tools were used. The mean number of publications per year using HRQOL instruments differed significantly between Pediatrics and the neurosurgical journals $(5.5$ vs $3.1, \mathrm{p}$ $=0.02$ ). Figure 1 shows the trend of HRQOL outcomes use in the pediatric neurosurgical journals over the past 10 years. The number of publications using HRQOL instruments showed a significant positive trend over time for Pediatrics $(\mathrm{B}=0.62, \mathrm{p}=0.02)$, but did not increase significantly over time for the 3 neurosurgical journals $(\mathrm{B}=$ $0.12, \mathrm{p}=0.5$ ). Child's Nervous System published the most neurosurgical HRQOL outcomes studies, comprising 18 (58.1\%) of the 31 articles. Overall, Pediatrics accounted for $55(64 \%)$ of 86 total studies that used HRQOL outcomes. Figure 2 demonstrates the number of articles published in each journal.

\section{Publishing Rate}

When we compare the total number of HRQOL articles published between Journal of Neurosurgery: Pediatrics 
8

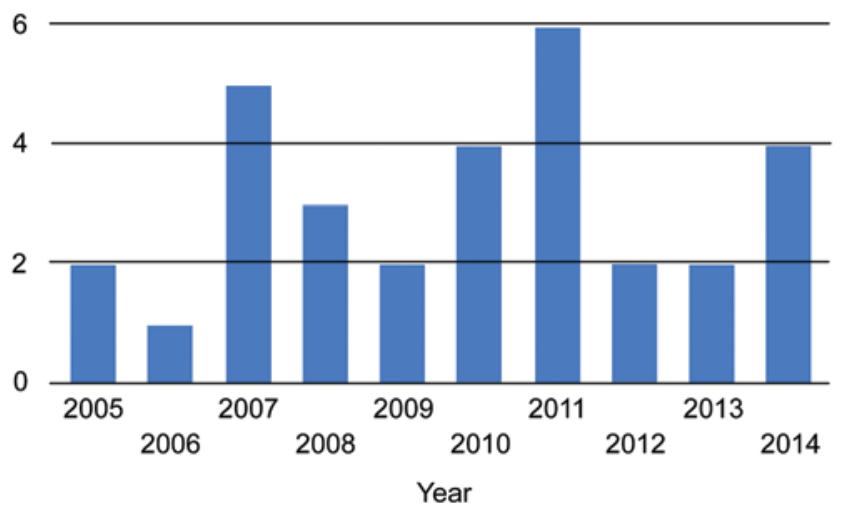

FIG. 1. Bar graph showing neurosurgical HRQOL outcome use by year. The numbers on the $y$ axis represent the number of publications. Figure is available in color online only.

(the pediatric neurosurgical journal with the highest impact factor) and Pediatrics (our benchmark) over the study period, we can get a sense of the proportion of studies using HRQOL instruments that are being published. There were 2106 articles published in the Journal of Neurosurgery: Pediatrics; 11 articles $(0.52 \%)$ addressing HRQOL topics were identified. Over the same time period, Pediatrics (8420 total articles, 55 identified as addressing HRQOL) had a statistically higher proportion of $0.65 \%(\mathrm{p}<0.05)$.

\section{Outcome Instruments, Frequency, and LOE}

Overall, a total of 46 different HRQOL outcomes in- struments were identified in our analysis of the literature. Many of these HRQOL outcomes used unvalidated tools created by authors for the particular study. Furthermore, several papers used multiple measures. The most common of these are categorized by type in Table 1 . The top HRQOL outcomes measures in order of frequency were Pediatric Quality of Life (PedsQL) (25 uses; 29.1\% of articles used this HRQOL outcomes tool), Health Utilities Index (HUI) (6 uses; 7\% of articles used this HRQOL outcomes tool), and the Hydrocephalus Outcome Questionnaire (HOQ) (6 uses; $7 \%$ of articles used this HRQOL outcomes tool) (Fig. 3 ). Custom-designed, unnamed, or unvalidated QOL measures were used in 17 articles (19.8\%).

An LOE of 4 was the most common among all articles (57 articles [66.3\%]) (Fig. 4). No reviewed neurosurgical article achieved an LOE $>4$; all articles with higher LOEs $(\geq 3)$ were found in Pediatrics. An LOE of 3 was the second most common (18 articles [20.9\%]), followed by an LOE of 2 (10 articles [11.6\%]) and an LOE of 1 (1 article [1\%]). An LOE of 1-the highest level of evidence-was not found in any of the pediatric neurosurgical articles (Fig. 5).

\section{Discussion}

The use of HRQOL outcomes instruments has not changed significantly in pediatric neurosurgical studies over the past 10 years. Although increased emphasis throughout the health care industry has been placed on measuring patient QOL, the use of HRQOL instruments in articles published in our best pediatric neurosurgical journals (such as the Journal of Neurosurgery: Pediatrics) does not compare favorably to high-quality studies published in Pediatrics during the same time period.

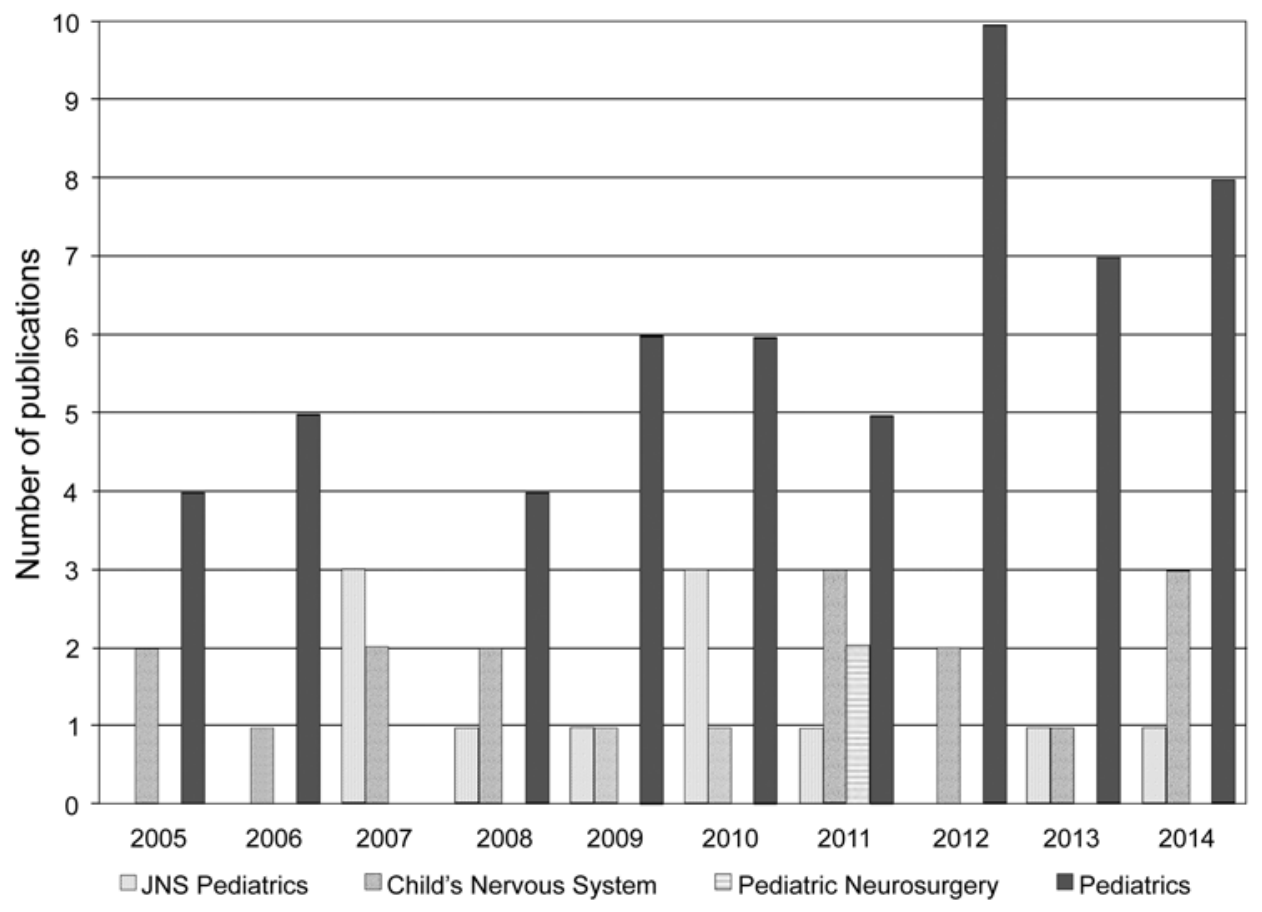

FIG. 2. Bar graph showing the HRQOL outcome use by journal and year. 
TABLE 1. The HRQOL instrument types and instruments used in 2005-2014

\begin{tabular}{|c|c|c|c|}
\hline Generic & $\begin{array}{l}\text { Region- } \\
\text { Specific }\end{array}$ & Disease-Specific & $\begin{array}{l}\text { Pain- } \\
\text { Related }\end{array}$ \\
\hline Fertigkeitenskala Münster-Heidelberg & None & $\begin{array}{l}\text { Pediatric Functional Assessment of Cancer Therapy- } \\
\text { Childhood Brain Tumor Survivor }\end{array}$ & None \\
\hline Quality of Life Questionnaire (QOL-Q) & & $\mathrm{HOQ}$ & \\
\hline Multi-Attribute Health Status Classification System, Mark II version & & Quality of Life in Epilepsy-10 & \\
\hline PedsQL Inventory & & Pediatric Asthma Quality of Life Questionnaire & \\
\hline $\mathrm{HUI}-2 / 3$ & & Pediatric Voice Handicap Index & \\
\hline \multicolumn{4}{|l|}{ ILK-MARSYS } \\
\hline \multicolumn{4}{|l|}{ KINDL } \\
\hline \multicolumn{4}{|l|}{ VAS } \\
\hline \multicolumn{4}{|l|}{ Child Health Questionnaire-Parent Form 50 (CHQ-PF50) } \\
\hline \multicolumn{4}{|l|}{ Dev Profile II } \\
\hline \multicolumn{4}{|l|}{ SF-36 } \\
\hline \multicolumn{4}{|l|}{$15 \mathrm{D}$} \\
\hline \multicolumn{4}{|l|}{ Child Health and IIIness Profile-Adolescent edition } \\
\hline \multicolumn{4}{|l|}{ TNO-AZL questionnaire for Adult's Health-Related Quality of Life } \\
\hline \multicolumn{4}{|l|}{ OSA-18 Quality of Life Questionnaire } \\
\hline \multicolumn{4}{|l|}{ KIDSCREEN-10 Index Score } \\
\hline \multicolumn{4}{|l|}{ SF-12 } \\
\hline \multicolumn{4}{|l|}{ Impact of Childhood IIIness } \\
\hline \multicolumn{4}{|l|}{ Preschool Children Quality of Life } \\
\hline \multicolumn{4}{|l|}{ Child Health Utility 9D } \\
\hline \multicolumn{4}{|l|}{ WHOQOL-BREF } \\
\hline $\begin{array}{l}\text { Dev = developmental; } \mathrm{HUI}-2 / 3=\mathrm{HUI} \text { versions } 2 \text { and 3; ILK-MARSYS = Inven } \\
\text { zur Qualitätssicherung und Therapieevaluation; KIDSCREEN = Screening fo } \\
\text { Public Health Perspective; KINDL = a German generic HRQOL instrument; } 0 \\
\text { The Netherlands Organization for Applied Scientific Research, Academic Me } \\
\text { sion; 9D, 15D = 9- and 15-dimensional instruments. }\end{array}$ & $\begin{array}{l}\text { zur Erfass } \\
\text { nd Promotic } \\
\text { A = Obstruc } \\
\text { cal Center L }\end{array}$ & $\begin{array}{l}\text { Ig der Lebensqualität bei Kindern und Jugendlichen-Marburge } \\
\text { of Health-Related Quality of Life in Children and Adolescents } \\
\text { ve Sleep Apnea; SF-12 =12-Item Short Form Health Survey; T } \\
\text { iden; VAS = visual analog scale; WHOQOL-BREF = WHOQOL }\end{array}$ & $\begin{array}{l}\text { System } \\
\text { European } \\
\text {-AZL = } \\
\text { rief ver- }\end{array}$ \\
\hline
\end{tabular}

Through the passage of the PPACA, physician and hospital reimbursement have been tied to patient-reported outcomes. The HOQ and the 36-Item Short Form Health Survey (SF-36) have emerged as frequently reported HRQOL outcomes tools in pediatric neurosurgical research. However, the frequent use of multiple uncommon, unnamed, and unvalidated instruments reflects the lack of standardization in the use of HRQOL instruments in pediatric neurosurgery.

\section{Definition of Outcome Measures}

Self-reported health outcomes aim to measure subjective HRQOL or health status from the viewpoint of the population or patient group itself. ${ }^{30}$ In the case of children or adolescents, this can be accomplished either by asking the children themselves for responses or by using proxy responders such as parents..$^{12,30}$

Self-reported health outcome measures came into being as a result of several factors. ${ }^{12,30}$ First, it is increasingly recognized that traditional biomedical outcomes needed to be supplemented by measures that take the patient's experience and concerns into account, particularly with regard to surgical diseases and associated treatment, where the intention is often to improve functioning and general QOL. ${ }^{7,935}$ Second, it is increasingly considered appropri- ate and desirable for patients' preferences and wishes to be taken into account in decision-making concerning their health care. ${ }^{30}$ Third, health care budget and policy makers face relentlessly rising pressure on resources. This has led to the growing use of cost-effectiveness evaluation, requiring evidence of benefits perceived by patients and their families, physicians, health care payers, and society as a whole. ${ }^{19,30}$

\section{Challenges in Measuring HRQOL in Children}

A number of key issues and definitions ${ }^{30}$ have an important bearing on the scope of this analysis. First, instruments can be classified as disease-specific or generic. Disease-specific measures, such as the HOQ, have been developed specifically for use with patients who have particular conditions or illnesses. These will be very relevant when comparing disease-specific results but will be limited in their ability to generalize to a broader pediatric population. On the other hand, generic instruments, such as PedsQL, are designed to measure aspects of health that are of universal importance. Therefore, they are appropriate for use across different patient populations and are potentially applicable to multiple pediatric populations, surgical or not.

Another key point is whether HRQOL outcomes instru- 


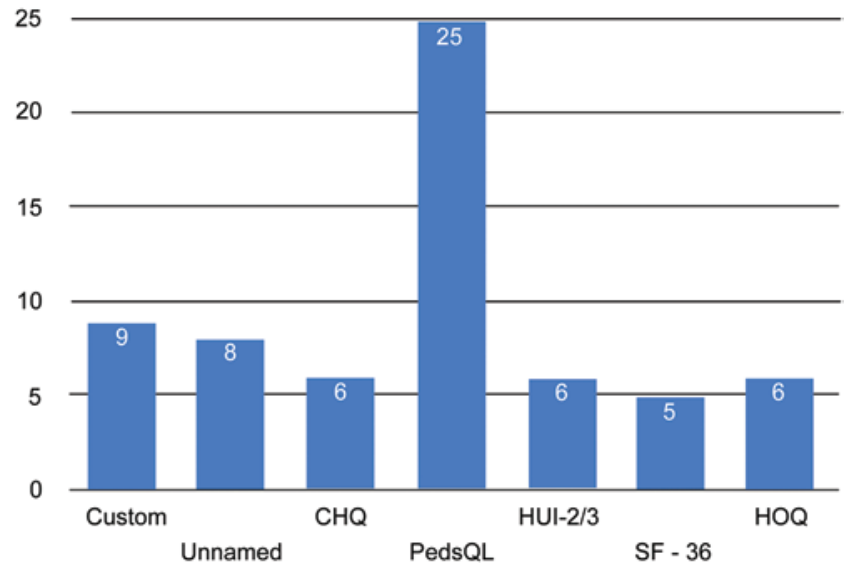

FIG. 3. Bar graph showing the $\mathrm{HRQOL}$ outcome prevalence. $\mathrm{CHQ}=$ Child Health Questionnaire; HUI-2/3 = HUI versions 2 and 3. Figure is available in color online only.

ments assess single dimensions of QOL, such as physical functioning, versus multiple dimensions such as physical health, mental health, and social well-being. The content of generic instruments has expanded to include social and emotional aspects of health as well as existential issues, aligning with the broad WHO definition of health: "a complete state of physical, mental, and social well-being, and not merely the absence of disease or infirmity." 33

As with adult counterparts, ${ }^{9}$ no uniform consensus on the theoretical framework for defining HRQOL in children $^{30}$ has been reached. Moreover, the question of whether children have the same underlying concept of QOL as adults, as well as whether "adult" instruments can be adapted and extrapolated for the pediatric age group, is unresolved. ${ }^{30}$ That is, in the adult age group, QOL is often associated with functional independence and economic productivity. Yet these measures may be irrelevant to a child's and a parent's perception of QOL. In addition, there have been major concerns about the accuracy and acceptability of parent-proxy ratings of pediatric patients' HRQOL. ${ }^{10,15,17,25}$

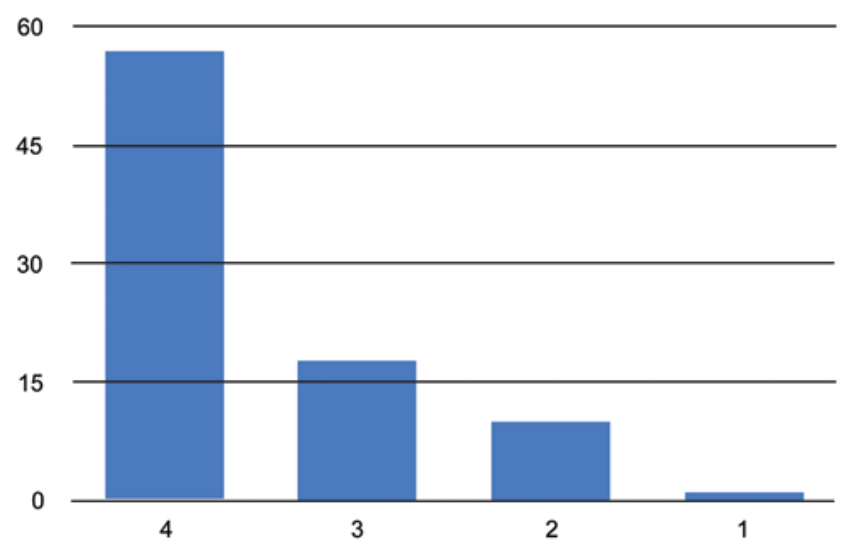

FIG. 4. Bar graph showing the LOE (represented by the numbers on the $x$ axis) of articles using HRQOL outcomes. $N=86$ articles. Figure is available in color online only.

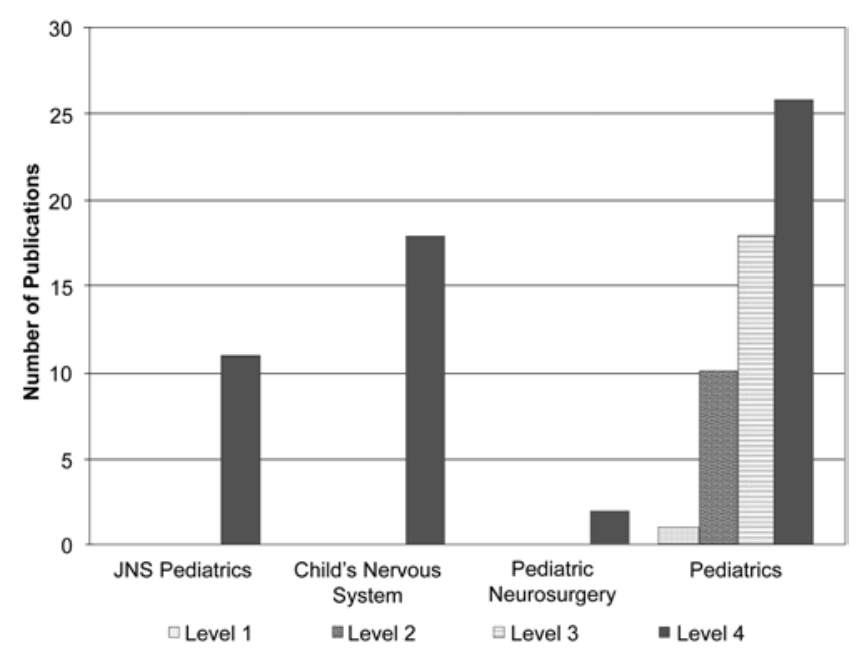

FIG. 5. Bar graph showing the LOE by journal. $N=86$ articles.

\section{Assessments Using HRQOL in Children With Neurodevelopmental Disorders}

A review ${ }^{23}$ of pediatric neurology HRQOL outcomes measures identified studies in the area of epilepsy, $,, 8,11,24$ spinal dysraphism, ${ }^{20}$ sequelae of prematurity, ${ }^{26-29}$ brain tumors, $, 3,4,6,13,14$ and headaches. ${ }^{17,18}$ The studies of epilepsy, neural tube defects, and headaches have used diseasespecific HRQOL measures, whereas studies of the sequelae of prematurity and of brain tumors applied global HRQOL instruments using specifically the HUI systems. ${ }^{23}$ The utility of other generic HRQOL instruments for children or adolescents has not been clearly tested in patients with neurodevelopmental disorders. ${ }^{1,2,21,31,32,34}$ Although there is considerable overlap between patient populations treated by pediatric neurologists and those treated by pediatric neurosurgeons, very few pediatric neurosurgical clinical studies use the HRQOL tools mentioned above. ${ }^{22}$ This serves as a call for future pediatric neurosurgical research to be more rigorous in incorporating HRQOL outcomes.

\section{Instrument Summaries The PedsQL}

This instrument is designed with a core set of 23 generic questions, with additional disease-specific modules. Core questions focus on multidimensional aspects of health. It is appropriate for a child to self-report from ages 5-18 years and for parents to proxy-report for children and adolescents ages $2-18$ years. Administration time can be less than 5 minutes. High reported reliability $(>0.88)$ has been noted. Multiple language translations are available.

\section{The $\mathrm{HOQ}$}

This tool is a 51-item questionnaire designed to capture the most significant health aspects in children living with hydrocephalus. It is a multidimensional assessment looking at physical, social, emotional, and cognitive aspects. A 10- to 15-minute administration time is typical, and the HOQ has a high reported reliability $(>0.88) .{ }^{16}$ 


\section{The HUI}

This patient-reported outcome is a family of generic preference-based systems for measuring comprehensive health status and HRQOL. It is multidimensional, providing a score for each dimension of health and a HRQOL score for overall health. Each dimension has 3 to 6 levels. The HUI systems describe nearly 1 million unique health states. Overall, HRQOL scores are on the conventional spectrum: dead (0.00) to perfect health (1.00). Multiple language translations are available. Its creators recommend HUI for children age 5 years or older.

\section{The SF-36}

This instrument is a nondisease-specific short-form survey with 36 questions, yielding an 8-scale profile of functional health and well-being. The questions assess multiple indicators of health, including function, distress and well-being, and self-evaluations of health. First released in its standard form in 1990, it has been used in numerous studies and countries since that time. The publishers of the SF-36 do not recommend its use in studies of children; instead, they suggest using the Child Health Questionnaire.

\section{Limitations of the Study}

Due to the sheer volume of articles published among the 4 reviewed journals during the chosen time period, not all articles could be read at length. Thus, we decided to select papers with a focus on HRQOL as reflected in the title and/or abstract. It is entirely likely that additional papers included some measure of HRQOL within the body of the results, but it was not feasible to search for all of these; therefore, there may be a bias toward underreporting the total use of HRQOL instruments in all published articles. Using the title as the primary tool for identifying target articles forced the focus to be on papers whose main topic was HRQOL.

Additionally, we restricted our review to 3 top pediatric neurosurgical journals and 1 large general-audience pediatric journal. Our aim was to compare the output of our field against a broader context, not necessarily to compare directly with other surgical subspecialties. Whereas a direct comparison with other pediatric surgical specialties may have resulted in more favorable results, it misses the intent of the paper, which was to examine an overall evolving trend in pediatric publications.

The difference in publication rates between the 3 surgical journals and 1 general pediatric journal may reflect editorial differences in the types of submitted or accepted papers. Unfortunately, we have no way to determine the difference between papers addressing HRQOL outcomes submitted for publication versus those that are ultimately accepted, and how that may differ between journals. Regardless, in this new evolving age of outcomes-based medicine, we would argue that as surgeons, we should be intimately involved in determining not only how to define and measure our own outcomes, but also what exactly "good" outcomes are for our specialty. Leaving such considerations to groups or individuals outside of pediatric neurosurgery seems short-sighted at best and dangerous at worst.

\section{Conclusions}

In this bibliometric analysis, we have demonstrated a scarcity of HRQOL outcome studies in pediatric neurosurgical research over the past 10 years, and have quantified the frequency of the most-used instruments. The results are disappointing at best; at worst, they show a striking disconnect between the forces that will shape the future of health care delivery and our field's understanding of the importance of participating in the conversation. By comparison, studies published in Pediatrics show a tendency toward greater use and more consistently applied measurement tools. In today's health care environment-cost conscious and patient centered-there is a need for more clinical studies using validated HRQOL outcome tools. Furthermore, there is a need to standardize HRQOL outcome measures used in pediatric neurosurgical research. We hope that this study provides the background data for that purpose.

\section{References}

1. Apajasalo M, Rautonen J, Holmberg C, Sinkkonen J, Aalberg V, Pihko H, et al: Quality of life in pre-adolescence: a 17-dimensional health-related measure (17D). Qual Life Res 5:532-538, 1996

2. Apajasalo M, Sintonen H, Holmberg C, Sinkkonen J, Aalberg V, Pihko H, et al: Quality of life in early adolescence: a sixteen-dimensional health-related measure (16D). Qual Life Res 5:205-211, 1996

3. Barr R, Pai M, Weitzman S, Feeny D, Furlong W, Rosenbaum $\mathrm{P}$, et al: A multiattribute approach to health-status measurement and clinical management illustrated by an application to brain-tumors in childhood. Int J Oncol 4:639-648, 1994

4. Barr RD, Simpson T, Whitton A, Rush B, Furlong W, Feeny DH: Health-related quality of life in survivors of tumours of the central nervous system in childhood-a preference-based approach to measurement in a cross-sectional study. Eur $\mathbf{J}$ Cancer 35:248-255, 1999

5. Batzel LW, Dodrill CB, Dubinsky BL, Ziegler RG, Connolly JE, Freeman RD, et al: An objective method for the assessment of psychosocial problems in adolescents with epilepsy. Epilepsia 32:202-211, 1991

6. Billson AL, Walker DA: Assessment of health status in survivors of cancer. Arch Dis Child 70:200-204, 1994

7. Bridwell KH, Berven S, Edwards C II, Glassman S, Hamill C, Schwab F: The problems and limitations of applying evidence-based medicine to primary surgical treatment of adult spinal deformity. Spine (Phila Pa 1976) 32 (19 Suppl):S135-S139, 2007

8. Cramer JA, Westbrook LE, Devinsky O, Perrine K, Glassman MB, Camfield C: Development of the Quality of Life in Epilepsy Inventory for Adolescents: the QOLIE-AD-48. Epilepsia 40:1114-1121, 1999

9. Cutler HS, Guzman JZ, Al Maaieh M, Connolly J, Skovrlj B, Cho SK: Patient reported outcomes in adult deformity surgery: a bibliometric analysis. Spine Deform 3:312-317, 2015

10. Czyzewski DI, Mariotto MJ, Bartholomew LK, LeCompte $\mathrm{SH}$, Sockrider MM: Measurement of quality of well being in a child and adolescent cystic fibrosis population. Med Care 32:965-972, 1994

11. Devinsky O, Westbrook L, Cramer J, Glassman M, Perrine K, Camfield C: Risk factors for poor health-related quality of life in adolescents with epilepsy. Epilepsia 40:1715-1720, 1999

12. Fitzpatrick R, Davey C, Buxton MJ, Jones DR: Evaluating patient-based outcome measures for use in clinical trials. Health Technol Assess 2:i-iv, 1-74, 1998 
13. Foreman NK, Faestel PM, Pearson J, Disabato J, Poole M, Wilkening G, et al: Health status in 52 long-term survivors of pediatric brain tumors. J Neurooncol 41:47-53, 1999

14. Glaser AW, Furlong W, Walker DA, Fielding K, Davies K, Feeny DH, et al: Applicability of the Health Utilities Index to a population of childhood survivors of central nervous system tumours in the U.K. Eur J Cancer 35:256-261, 1999

15. Guyatt GH, Juniper EF, Griffith LE, Feeny DH, Ferrie PJ: Children and adult perceptions of childhood asthma. Pediatrics 99:165-168, 1997

16. Kulkarni AV, Rabin D, Drake JM: An instrument to measure the health status in children with hydrocephalus: the Hydrocephalus Outcome Questionnaire. J Neurosurg 101 (2 Suppl):134-140, 2004

17. Langeveld JH, Koot HM, Loonen MC, Hazebroek-Kampschreur AA, Passchier J: A quality of life instrument for adolescents with chronic headache. Cephalalgia 16:183-196, 137, 1996

18. Langeveld JH, Koot HM, Passchier J: Headache intensity and quality of life in adolescents. How are changes in headache intensity in adolescents related to changes in experienced quality of life? Headache 37:37-42, 1997

19. McCarthy I, Hostin R, O'Brien M, Saigal R, Ames CP: Health economic analysis of adult deformity surgery. Neurosurg Clin N Am 24:293-304, 2013

20. Parkin PC, Kirpalani HM, Rosenbaum PL, Fehlings DL, Van Nie A, Willan AR, et al: Development of a health-related quality of life instrument for use in children with spina bifida. Qual Life Res 6:123-132, 1997

21. Raphael D, Rukholm E, Brown I, Hill-Bailey P, Donato E: The Quality of Life Profile-Adolescent Version: background, description, and initial validation. J Adolesc Health 19:366-375, 1996

22. Rocque BG, Bishop ER, Scogin MA, Hopson BD, Arynchyna AA, Boddiford CJ, et al: Assessing health-related quality of life in children with spina bifida. J Neurosurg Pediatr 15:144-149, 2015

23. Ronen GM, Rosenbaum MP, Streiner DL: Outcome measures in pediatric neurology: why do we need them? J Child Neurol 15:775-780, 2000

24. Ronen GM, Rosenbaum P, Law M, Streiner DL: Healthrelated quality of life in childhood epilepsy: the results of children's participation in identifying the components. Dev Med Child Neurol 41:554-559, 1999

25. Ronen GM, Streiner DL, Rosenbaum P: Health-related quality of life in children with epilepsy: development and validation of self-report and parent proxy measures. Epilepsia 44:598-612, 2003

26. Saigal S, Feeny D, Furlong W, Rosenbaum P, Burrows E, Torrance G: Comparison of the health-related quality of life of extremely low birth weight children and a reference group of children at age eight years. J Pediatr 125:418-425, 1994

27. Saigal S, Feeny D, Rosenbaum P, Furlong W, Burrows E,
Stoskopf B: Self-perceived health status and health-related quality of life of extremely low-birth-weight infants at adolescence. JAMA 276:453-459, 1996

28. Saigal S, Rosenbaum P, Stoskopf B, Hoult L, Furlong W, Feeny D, et al: Comprehensive assessment of the health status of extremely low birth weight children at eight years of age: comparison with a reference group. J Pediatr 125:411-417, 1994

29. Saigal S, Stoskopf BL, Feeny D, Furlong W, Burrows E, Rosenbaum PL, et al: Differences in preferences for neonatal outcomes among health care professionals, parents, and adolescents. JAMA 281:1991-1997, 1999

30. Schmidt LJ, Garratt AM, Fitzpatrick R: Instruments for Children and Adolescents: A Review. Report to the Department of Health (July 2001). (http://phi.uhce.ox.ac.uk/ pdf/phig_children_report.pdf) [Accessed May 4, 2016]

31. Starfield B, Bergner M, Ensminger M, Riley A, Ryan S, Green B, et al: Adolescent health status measurement: development of the Child Health and Illness Profile. Pediatrics 91:430-435, 1993

32. Stein RE, Jessop DJ: Functional status II(R). A measure of child health status. Med Care 28:1041-1055, 1990

33. Ustün BT, Jakob R: Calling a spade a spade: meaningful definitions of health conditions. Bull World Health Organ 83:802, 2005

34. Varni JW, Seid M, Rode CA: The PedsQL: measurement model for the pediatric quality of life inventory. Med Care 37:126-139, 1999

35. Yadla S, Maltenfort MG, Ratliff JK, Harrop JS: Adult scoliosis surgery outcomes: a systematic review. Neurosurg Focus 28(3):E3, 2010

\section{Disclosures}

The authors report no conflict of interest concerning the materials or methods used in this study or the findings specified in this paper.

\section{Author Contributions}

Conception and design: Jea. Acquisition of data: Hansen, Vedantam. Analysis and interpretation of data: Jea, Hansen, Vedantam. Drafting the article: Jea, Hansen. Critically revising the article: Jea, Briceño, Lam. Reviewed submitted version of manuscript: Jea. Approved the final version of the manuscript on behalf of all authors: Jea. Administrative/technical/material support: Luerssen.

\section{Correspondence}

Andrew Jea, Division of Pediatric Neurosurgery, Texas Children's Hospital, Department of Neurosurgery, 6621 Fannin St., CCC 1230.01, 12th Fl., Houston, TX 77030.email: ahjea@ texaschildrens.org. 